\title{
Proactive or reactive marketing? The influence of the Internet on direct marketing, Paper 3
}

Received: 6th April, 2001

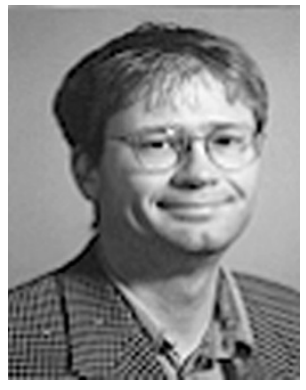

\begin{abstract}
Alan Tapp
is senior lecturer in marketing at Bristol Business School. He has over 13 years' experience in commercial and academic marketing positions. He is the author of 'Principles of direct and database marketing' and has over 20 publications in the fields of direct marketing, branding, charity marketing and, latterly, sports marketing. He has advised and trained companies as diverse as The Royal Mail and Coventry City Football Club. His major current interests are the strategic underpinnings of e-commerce, and sports marketing.
\end{abstract}

Abstract The Internet is set to have an influence on direct and database marketing which is more profound than its standing as merely another media option. A number of writers have already commented on the Internet's facility to shift power from businesses to customers, and hence change customers' behaviour. For example, it could be that increasingly it will be customers who drive the process of going to market, and they who lead the contact with businesses, rather than the other way around. For businesses too, the Internet may change ways of working, by facilitating information flows such that information management becomes ever more important for companies.

This final paper (of a series of three) reviews these and other Internet-related issues and discusses how they will affect direct and database marketing. One possibility is that instead of database marketers attempting to predict customer behaviour, a mixed approach is taken which allows customers to lead the contact, and this contact triggers a further marketing response from the business. Strategically, the company is then mixing reactive and proactive marketing to best advantage. A model describing this change is offered for further debate.

Dr Alan Tapp

Bristol Business School, University of the West of England, Frenchay Campus, Coldharbour Lane, Bristol BS16 1QY, UK.

Tel: +44 (0)117344 3439; Fax: +44 (0)117 3442289 ; e-mail:

Alan.Tapp@uwe.ac.uk

\section{INTRODUCTION}

Making predictions about anything is fraught with difficulty. Predicting the future role of the Internet in business is a recipe for failure on a bigger scale. Those who predicted FTSE success for dot.coms are currently licking their wounds, but the role for academics is to try and look behind the wild mood swings of speculators in order to help set the foundations for new principles. In this spirit, this paper reviews the literature on the Internet that direct marketers should be concerned with, and then proposes a small number of key areas that require further development.

In assessing these, it is necessary to be mindful of both changes in customer behaviour and changes in company practice. Hence the discussion is divided into these two areas, and changes in customer behaviour are examined first.

\section{CHANGES IN CUSTOMER BEHAVIOUR}

Bill Gates called the Web 'friction free capitalism'. What he meant by this was 
that in traditional, non-Internet markets, there is what might be termed high 'transaction isolation'. In other words, consumers buy without full knowledge of alternatives, often with a high inertia barrier. Businesses take advantage of this laziness and charge high prices knowing that customers will not look around too much.

Gates felt, however, that this is set to change. His assertion echoes that of The Economist in 1997 which said that 'the biggest change that the Internet will bring is the shift in power from merchant to consumer'. Mitchell, in his excellent discussion about the impact of the Web on business, painted a picture of a consumer in charge of the process of going to market. ${ }^{1}$ This shift in power will come about because of the ease of searching for alternatives that the Net provides. The customer can make price/value comparisons very quickly. Everything is just a 'mouse click' away. This is predicted to increase 'flea market' style browsing. ${ }^{2}$ Like casual shoppers examining antique stalls on a Sunday morning, Internet surfers enjoy the experience itself, as well as the possible act of purchase. For Zwass, the challenge for business is how to engage users by promoting the transition from non-user to passive browser and then active user of websites. ${ }^{3}$

Friction-free capitalism also aptly describes the ease with which buyers and sellers find each other on the Net. This is illustrated by the growth of online auction houses. Increasingly, in markets such as tourism, customers are able to treat the Internet as a one-stop shop, in which they can gather information, make comparisons, then make a purchase all in one session. It is this ease of comparison which means that an 'average' offer will therefore not survive - as Hamel and Sampler put it: the Internet is a noose for mediocrity. ${ }^{4}$
There are, however, even more profound switches of power possible. In traditional markets, information is passed 'down' to customers from companies taking advantage of their control of the act of going to market. The Internet's low cost of access, however, allows customers (or agents acting on their behalf) to take control of going to market. In addition, the Internet caters for easy 'sideways' information flows, allowing customers to talk to each other, forming communities of interest extremely quickly. ${ }^{5}$ Instead of only one marketplace where companies tell customers what they have to sell and customers react or choose as a result, Berryman et al. ${ }^{6}$ suggest there are now three marketplaces:

- the sellers' marketplace, the traditional model

- the neutral marketplace, for example, an on-line auction house

- the customers' marketplace, for example a buying club.

The latter two are of particular interest when considering how the Internet makes things different. As customers get more used to their new found abilities to act as a group, these shifts in power will only increase. This is already leading to new types of behaviour in all sorts of business, leisure and political situations. For example, the fuel protests of autumn 2000 in the UK were coordinated through quickly formed websites and e-mail groups; protest groups of long standing such as the League Against Cruel Sports have long used the interactivity of websites to their advantage.

Mitchell hinted at the implications of these changes to direct marketers. As seen in paper 1 of this series, direct marketing strategy is predicated around the idea of customer management. Here, 
Model 1

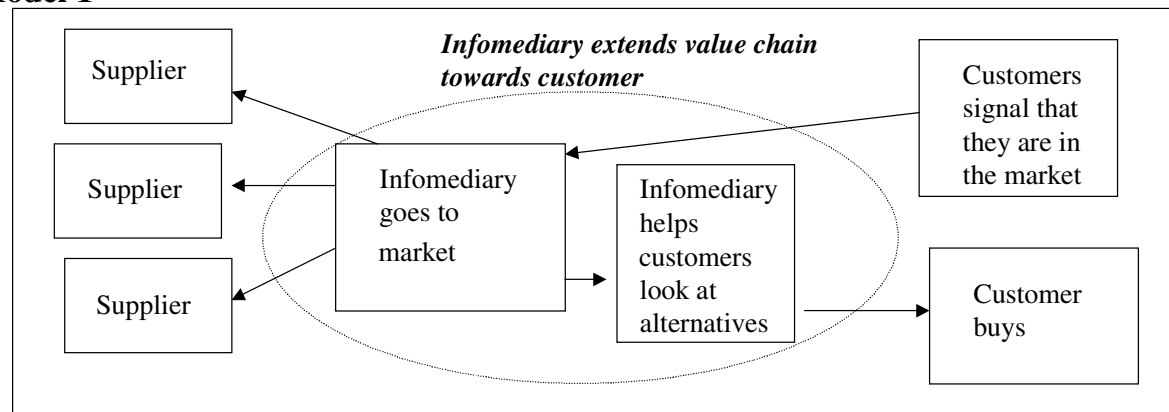

Model 2

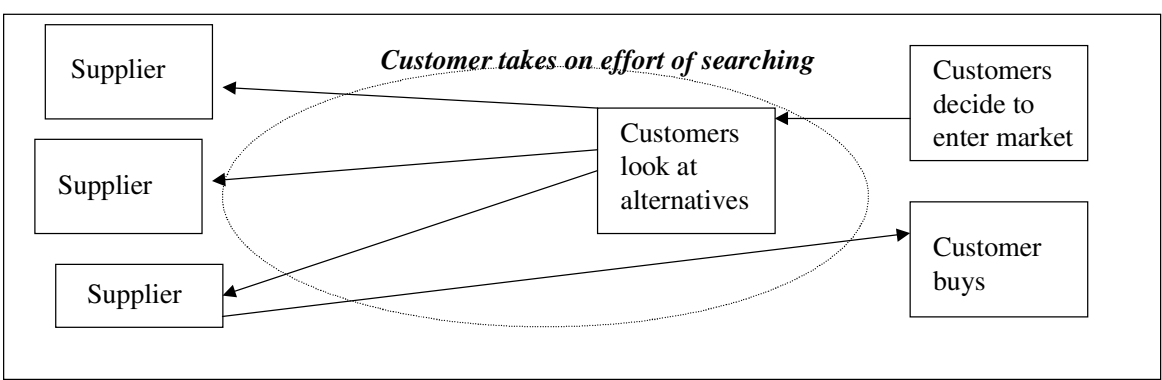

Figure 1: The infomediary model

companies use their transaction histories with customers to understand and predict customers' needs. Data tell businesses what customers want, when they want it, how much they would be worth to the company and therefore how much value the company could share to enhance loyalty. Mitchell suggested, however, that with the new world order the Internet is enabling, customers will not put up with being 'managed'. Traditionally, the power in the relationship lay squarely with suppliers who would decide who to target, what offer to make, and when to pull out of the deal if it did not suit them and so on. In the Internet-driven marketplace, customers will have the upper hand.

\section{THE RISE OF INFOMEDIARIES}

The impression gained then is that the Net hands choice and control to the consumer. Choice and control are, however, double-edged swords:

consumers often do not have the time, patience or perhaps ability to work out the best offer to suit them. What many of them will probably want is to take advantage of the better value the Net can offer them, but help in doing this. This opens up the field to infomediaries. ${ }^{7,8}$

Traditional intermediaries such as brokers act on behalf of the sellers rather than consumers. In contrast, infomediaries will act on behalf of consumers. They take on consumers as clients and gather data about their needs across a wide variety of categories. They would also record data about purchases made through themselves and hence increase their knowledge over time about consumers, in the same way as a traditional database. Infomediaries are in a much more powerful position than traditional database marketers, however, as they can record data across 
competitors and across sectors, getting a holistic picture of consumers' purchases and preferences. The excitement may grow as these developments allow a revival of Peppers' one-one concept ${ }^{9}$ but this time with the database marketer acting on behalf of the customer. Infomediaries would gather information from customers about their preferences, how much they have to spend, then scour the Web for the best deal to meet that need. They add value by taking on the customers' role of going to market.

As Mitchell points out, learning about customer needs will take place across a range of suppliers, not just for one supplier. A kind of database 'nirvana' can then be dreamt of, with a customer's every whim being anticipated, searched for and met, facilitated by a gigantic tide of personal preferences and past behaviour across dozens of different sectors, all held for thousands of business or personal customers.

At the time of writing, however, infomediation is starting to happen, but as yet is undeveloped. Companies such as populardemand.com, waysearch.com and indeed priceline.com have all explicitly stated this as their intention while others such as Intuit are well placed to enter the market. Infomediaries are likely to thrive in complex product or service sectors, where choice is high and where detailed information is needed before making a decision. Database marketing-led infomediaries may have a better chance where there is a high possibility of the product or service being tailored for the individual, for example health care or household services like child care. Markets such as financial services, travel, tourism and auto manufacture are being attacked because their combination of information intensity, high search costs, pricing distortion and confusion tactics have made it difficult for customers to find the best deal at the time they need it. These are the prime sectors for early players in the infomediary business, for example Travelocity.com and expedia.com.

The discussion so far would suggest that infomediation is a sure bet for growth. There are hurdles to jump yet, however. The most critical issue of all is trust. The central question is this: why should customers trust a company to place their interests above those of the supply side? The possibility is that large, powerful brands from traditional industries may enter this market. Thus the likes of IBM, BT or supermarkets like Tesco could consider themselves as players. It will surely, however, be a tall order for these players to transform their brands from their current status to that of an independent 'customer champion'. The second problem is that infomediaries may incur high costs of management time in offering customers help and may need to charge a high price for that help. If the costs of proactive marketing based on predicting customers needs is too high (as seems to be the case with traditional one-to-one marketing) then infomediaries may subside into mere 'virtual retailers' pasting up what they claim will be the best offers. Thirdly, there are many sectors in which suppliers and their offers are difficult to compare and are therefore better examined by customers themselves rather than intermediaries. The sectors with most potential for redesign will be commodity markets, for example passenger air travel.

At this point, the reader might conclude that with a prediction of power shifting to customers due to the ease of switching, low costs of searching and low costs of information gathering, the outlook does not look bright for traditional businesses. The Internet may, however, also impact positively on companies. The next part of the paper reviews these changes. 


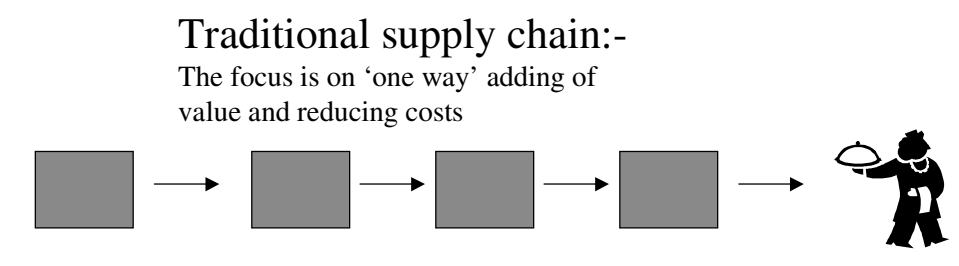

The e-commerce "demand chain":-

The process starts with customers. Their information impacts on the value chain

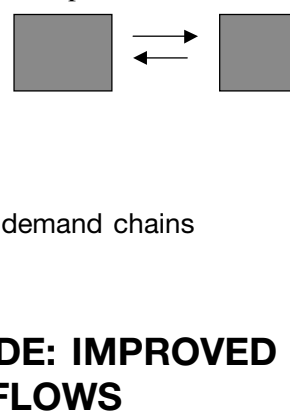

INFORMATION FLOWS

The chances are that businesses will have to prioritise information processing and the management of knowledge even more than they do at present, because information flows will become more important in keeping businesses competitive. Sahay, Gould and Barwise characterise the move into Internet markets as being from what they describe as atom-based business (the physical world) to BIT-based business (the virtual world). ${ }^{10}$ This will necessitate a change in emphasis towards information-based marketing (ie the marketing strategies and tactics are driven by customer interactions) where the interactive exchange of information, and the content, quality and speed of responses can be a source of competitive advantage. On a similar theme, Walters and Lancaster contend that

'information is the glue that holds together the structure of all businesses. A company's value chain consists of all the activities it performs to design, produce and market its product. But the value chain also includes all the information that flows within a company and its suppliers, distributors and customers' ${ }^{11}$

Walters and Lancaster make interesting points about information which are of great strategic value to direct marketers. They point out that there is a trade off between information reach and richness. Reach is simply the number of people exchanging information. Richness refers to the amount of information going from sender to receiver, the extent of its customisation, and the extent to which interaction is possible. The idea is that as information flows become more valuable, it is more difficult to manage these flows in a mass market. This has underlined the difficulties that companies have had in implementing one-to-one marketing.

The advent of new technology should, however, allow for an increased amount of richness at decreased cost, allowing for more reach. This has huge implications for the company's supply chain, as shown in Figure 2.

The Internet allows customers to initiate the value chain process, and to 
infuse it with information about their needs. This supports a greater amount of mass customisation than has existed up to now.

Earlier in the paper the consequences for customers of easier comparison of suppliers were discussed. As would be expected there are also internal ramifications within the company. For instance, in business markets direct, Web-based sales have led to a changed role for sales forces. Their role has evolved so that service, or consultancy, is a priority. Interestingly, Oracle have found that with reduced sales force involvement in the sale itself, there is less deal making and hence more stable pricing because of the transparency of the Net.

Fraser, Fraser and McDonald pointed out the importance of the Web to internal workings as well as customer interfaces. First, they felt that intranets and extranets (as well as the Internet) will facilitate lower costs in purchasing departments. Secondly, there will be a reduction in intermediation costs associated with wholesale and retail activities. Finally, there will be a lowering of supply and logistics costs by curbing time and effort in these operations. ${ }^{12}$ There may, however, be a disadvantage in being the first mover in the use of e-commerce because of the high costs of establishing capital and human resources. In other words, Internet technologies have high learning costs. It may be that the boom in all e-commerce stocks that marked the turn of the century will subside as many first movers do not succeed.

Evans and Wurster contended that

'as it becomes easier for customers to switch from one supplier to another - something that is now commonplace on the net - the competitive value of traditional approaches such as one-stop-shopping and established relationships will drop. Cross-selling will become more difficult. Competitive advantage will be determined product by product and so providers with broad product lines will lose ground to focused specialists'. ${ }^{13}$

If this scenario becomes reality the entire concept of customer loyalty to one company, leading to lowered costs of selling for that company, may need re-examining.

An alternative view is that as the trend of customers buying from remote sources increases the importance of branding may increase as trust in intangible suppliers becomes more important. Evans and Wurster's comments about relationships may, however, provide a stern warning to advocates of relationship marketing in consumer markets. It also has implications for database marketers in that it suggests that for database marketers using the Internet, the best approach may be to concentrate on exchanging information with customers and providing enhanced value based on this information, rather than possibly weak attempts at relationship building.

One example of this is the recording of supermarket shopping lists on websites used by customers by the store. The keying in of a list for the first time may take as long as couple of hours. The reward comes, however, with subsequent shopping as the database has saved the previous list, which can be brought onto screen by the shopper. The service for existing customers has therefore improved markedly.

The final part of this paper moves from the above review and synthesis of existing material and uses it to create a speculative model of two aspects of e-commerce that are of vital importance to direct marketers. The first model examines the extent to which the traditional model of proactive (predictive) marketing favoured by database marketers 
should be adapted. The second reacts to the huge data implications of business on the Internet, and asks what businesses should record and use.

\section{SHOULD COMPANIES ADOPT REACTIVE OR PROACTIVE MARKETING?}

The weakness of the proactive 'customer management' model in traditional database marketing was always that it was a set of 'guesses' by the company about customer needs (timing, product) and preferences for that supplier (driven by one company when the customer possibly uses others as well). Therefore there was a lower chance of success in efficiently going to market - it was more a case of the company 'giving itself a chance' rather than acting on firm instructions from the customer. The power of the Internet may lie in its ability to mix up reactive and proactive marketing. Amazon.com lets the customer tell it when the customer is ready to enter the market for books (reactive marketing). It then offers customers choices of books based on previous customer transactions (database-driven proactive marketing). Customers then take back control and complete the transaction as it suits them, without pressure. This is potentially a powerful way of doing business.

With infomediaries, another slight variation is possible. Customers may initiate the action by contacting the infomediaries, who then take over and manage the transaction on behalf of the customer. They may use the immediate customer instruction, and react to that. In this sense infomediaries are practising 'customer management', but with the customers' consent and knowledge. The customer has asked to be 'managed' because they see this management as a service to them: infomediaries are carrying out a search on their behalf. Infomediaries may also proactively use customer data to search out offers for customers - thus mimicking traditional database marketing - but with two differences. Infomediaries search across a range of suppliers rather than just one. They also gather data about customer preferences for a range of suppliers rather than one. As Mitchell says, it may therefore be with the infomediary that database marketing at last finds its true home.

\section{RECORDING INTERACTIONS FOR DATABASE MARKETING}

Much has been said about 'interactive marketing'. Indeed, some consulting organisations see this as the next 'big thing' and are positioning themselves accordingly. But what does interactive marketing actually mean? In what way is it different to any other form of marketing? The roots of it may be traced to Hoffman and Novak's seminal work. ${ }^{14}$ They pointed out that the Internet allows a change from a one-to-many model of communication (eg television advertising) to a one-to-one or even many-to-many model (eg interactive 'chatlines' on the Net). This allows for significant interaction between customer and firm. For example, banks may offer customers the chance to record or plan their finances, bookstores such as Amazon.com allow customers the chance to search for titles quickly, and to post their own reviews on the site. Dell Computers uses the Internet as a way of displaying help manuals.

Not all examples of interactive marketing, however, are paradigm changes. In both reverse and standard auctions suppliers and buyers are interacting with each other in a way which mirrors face-to-face situations, for example a traditional fruit market. It is 


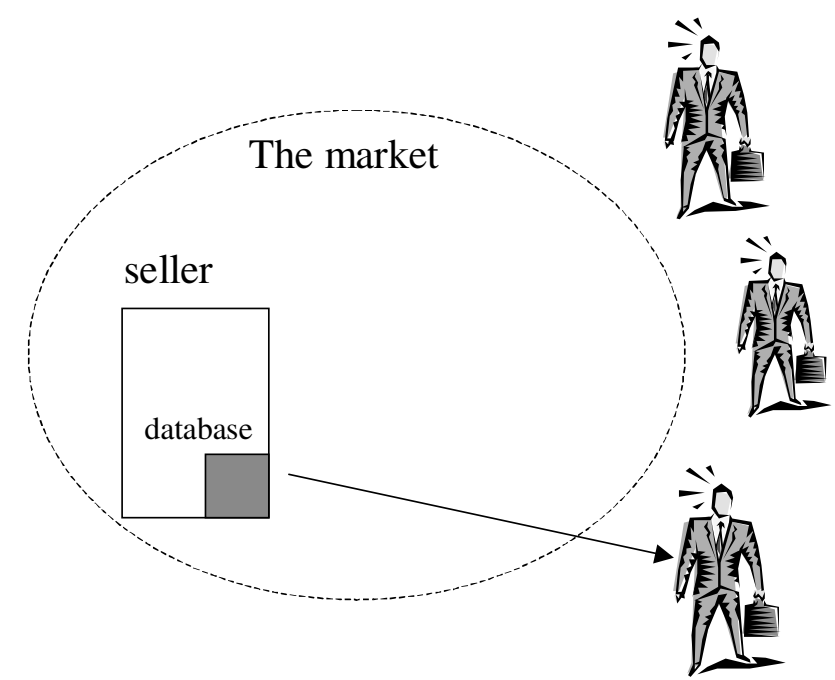

Seller tries to predict when buyer is about to enter the market

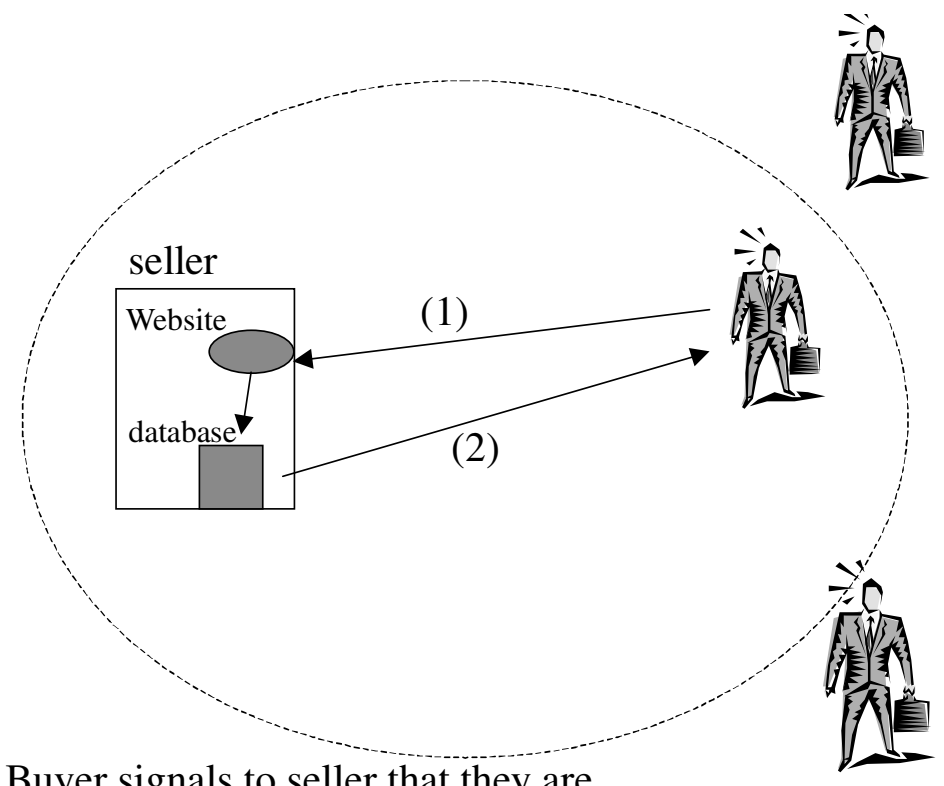

Buyer signals to seller that they are in the market by contacting website

Figure 3: Reacting to website contact

therefore necessary to be careful not to lump in all aspects of business through the Internet as being wildly innovative, when much of it is merely replicating existing business practice, but through a new medium. Examples include sellers letting customers fill their own baskets with goods. This may well be a good efficient use of the Internet, but as a customer/supplier way of interacting it is exactly the same as mail order shopping. Other examples of 'interactivity' are 
insurance companies such as Eagle Star Direct and Direct Line asking consumers for information and offering quotes for car and house insurance. While this is more interactive than using, say, direct mail (as it is possible to get instant feedback from the supplier saying that the order has been accepted), it is less interactive than the telephone.

More saliently, it is necessary to ask to what extent firms should attempt to record interactions (as against transactions), learn from these contacts, and then change the marketing to that individual as a result. Sceptics would argue that this is never going to be realistic as the management of such a process will be too expensive and customers do not require such minute segmentation. On the other hand, it has already been seen from the work of Peppers that such ideas may have possibilities. Perhaps somewhere in between recording all interactions and studying them, and recording none at all may lie a reasonable compromise, so that there is two-way link between customer interactions on the Net and any database marketing activity driven by it. In this instance there will be a need to distinguish transactions and non-transaction interactions, and to decide the worth of managing such data. In the author's opinion, however, there is a distinct danger of data overload here. It is a reminder of the well-known statistic that, worldwide, more information has been produced in the last 30 years than in the previous 5,000. According to Gamble, Stone and Woodcock the amount of information generated in world commerce already doubles every five years. ${ }^{15}$ The growth of electronic commerce will only accelerate this. The Achilles heel of direct and database marketing is arguably, however, not the recording of data, it is the profitable use of them.

\section{CONCLUSION}

While much has been written about the Internet, less has been said about its strategic implications for the future role of direct and database marketing. This paper began by reviewing the key issues that the literature has raised that are of concern to database marketers. By examining first the impact of the Internet on consumer behaviour and secondly its impact on business practice, key issues were identified. These were first the shift in power to consumers of the process of going to market. This may necessitate businesses undertaking strategies such as implementing a mixed model of reactive and proactive marketing. Secondly, there may emerge a new class of intermediary known as infomediaries. Customer trust, and hence branding, is, however, likely to be vital in ensuring the success of such organisations.

The key thing to affect business practice will be the greater ease with which information will flow around the business. The hard job for businesses will be how best to organise and use that information. This paper has suggested that a hard look needs to be taken at non-transaction data and if necessary a decision made not to record more casual contact-related data. If, however, one-to-one marketing is re-established as a real option by leading edge companies, then such data may be valuable. Overall, it is hoped that this paper has been of some help in advancing the discussion about the effect of the Internet on direct marketing.

\section{References}

1 Mitchell, A. (2000) 'In one to one marketing, which one comes first?' Interactive Marketing, pp. 354-368.

2 Belk, R.W., Sherry, J. F. and Wallendorf, M. A. (1988) 'Naturalistic enquiry into buyer and seller behaviour at a swap meet', Journal of Consumer Research, Vol. 14, No. 4, pp. 449-70. 
3 Zwass, V. (1998) 'Structure and macro-level impacts of electronic commerce: From technological infrastructure to electronic marketplaces', http://www.mhhe.com/business/ mis/zwass/ecpaper.html, accessed 30th April, 1999.

4 Hamel, G. and Sampler, G. (1998) 'The e-corporation', Fortune, 7th December.

5 Mitchell (2000) op. cit.

6 Berryman, K., Harrington, L., Layton-Rodin, D. and Rerolle, V. (1998) 'Electronic commerce three emerging strategies', McKinsey Quarterly, No 1.

7 Hagel, J. (1999) 'Net gain: Expanding markets through virtual communities', Journal of Interactive Marketing, Vol. 13, No. 1, Winter.

8 Mitchell (2000) op. cit.

9 Rogers, M. and Peppers, D. (1993) 'The one-to-one future', Piatkus, USA.

10 Sahay, A., Gould, J. and Barwise, P. (1998) 'New interactive media: Experts' perceptions of opportunities and threats for existing businesses', European Journal of Marketing, Vol. 32, No. 7/8, pp. 616-28.

11 Walters, D. and Lancaster, G. (1999) 'Using the Internet as a channel for commerce', Management Decision, Vol. 37, Iss. 10.

12 Fraser, J., Fraser, N. and McDonald, F. (2000) 'The strategic challenge of electronic commerce', Supply Chain Management, Vol. 5, Iss. 1.

13 Evans, P. B. and Wurster, T. S. (1997) 'Strategy and the new economics of information', Harvard Business Review, September/October.

14 Hoffman, D. L. and Novak, T. P. (1996) 'Marketing in hypermedia computer-mediated environments: Conceptual foundations', Journal of Marketing, Vol. 60, No. 7, pp. 50-68.

15 Gamble, P., Stone, M. and Woodcock, N. (1999) 'Up close and personal? Customer relationship marketing@work', Kogan Page, London. 